

\section{A}

\section{Enfoque y alcance}

La Revista de Arquitectura (ISSN 1657-0308 Impresa y E-ISSN 2357-626X en línea) es una publicación seriada de acceso abierto, arbitrada mediante revisión por pares (doble ciego) e indexada, en donde se publican resultados de investigación originales e inéditos.

Está dirigida a la comunidad académica y profesional de las áreas afines a la disciplina. Es editada por la Facultad de Diseño y el Centro de Investigaciones (CIFAR) de la Universidad Católica de Colombia en Bogotá (Colombia).

La principal área científica a la que se adscribe la Revista de Arquitectura según la OCDE es:

Gran área: 6. Humanidades

Área: 6.D. Arte

Disciplina: 6D07. Arquitectura y Urbanismo

También se publican artículos de las disciplinas como 2A02, Ingeniería arquitectónica; 5G03, Estudios urbanos (planificación y desarrollo); 6D07, Diseño.

Los objetivos de la Revista de Arquitectura son:

- Promover la divulgación y difusión del conocimiento generado a nivel local, nacional e internacional

- Conformar un espacio para la construcción de comunidades académicas y la discusión en torno a las secciones definidas.

- Fomentar la diversidad institucional y geográfica de los autores que participan en la publicación.

- Potenciar la discusión de experiencias e intercambios científicos entre investigadores y profesionales.

- Contribuir a la visión integral de la arquitectura, por medio de la concurrencia y articulación de las secciones mediante la publicación de artículos de calidad.

- Publicar artículos originales e inéditos que han pasado por revisión de pares, para asegurar que se cumplen las normas éticas, de calidad, validez científica, editorial e investigativa.

- Fomentar la divulgación de las investigaciones y actividades desarrolladas en la Universidad Católica de Colombia.
Palabras clave de la Revista de Arquitectura: arquitectura, diseño, educación arquitectónica, proyecto y construcción, urbanismo.

Idiomas de publicación: español, inglés, portugués y francés.

Título abreviado: Rev. Arquit.

Titulo corto: RevArq

\section{Políticas de sección}

La revista se estructura en tres secciones correspondientes a las líneas de investigación activas y aprobadas por la institución, y dos complementarias, que presentan dinámicas propias de la Facultad de Diseño y las publicaciones relacionadas con la disciplina.

CULTURA Y ESPACIO URBANO. En esta sección se publican los artículos que se refieren a fenómenos sociales en relación con el espacio urbano, atendiendo aspectos de la historia, el patrimonio cultural y físico, y la estructura formal de las ciudades y el territorio.

Proyecto ARQUitectónico y URBANO. En esta sección se presentan artículos sobre el concepto de proyecto, entendido como elemento que define y orienta las condiciones proyectuales que devienen en los hechos arquitectónicos o urbanos, y la forma como estos se convierten en un proceso de investigación y nuevo de conocimiento. También se presentan proyectos que sean resultados de investigación, los cuales se validan por medio de la ejecución y transformación en obra construida del proceso investigativo. También se contempla la publicación de investigaciones relacionadas con la pedagogía y didáctica de la arquitectura, el urbanismo y el diseño.

TECNOLOGÍA, MEDIOAMBIENTE Y SOSTENIBILIDAD. En esta sección se presentan artículos acerca de sistemas estructurales, materiales y procesos constructivos, medioambiente y gestión, relacionados con los entornos social-cultural, ecológico y económico.

DESDE LA FACULTAD. En esta sección se publican artículos generados en la Facultad de Diseño, relacionados con las actividades de docencia, extensión, formación en investigación o internacionalización, las cuales son reflejo de la dinámica y de las actividades realizadas por docentes, estudiantes y egresados; esta sección no puede superar el $20 \%$ del contenido.

TExTos. En esta sección se publican reseñas, traducciones y memorias de eventos relacionados con las publicaciones en Arquitectura y Urbanismo.

\section{A FRECUENCIA DE PUBLICACIÓN}

Desde 1999 y hasta el 2015, la Revista de Arquitectura publicó un volumen al año, a partir del 2016 se publicarán dos números por año en periodo anticipado, enero-junio y julio-diciembre, pero también maneja la publicación anticipada en línea de los artículos aceptados (versión Post-print del autor).

La Revista de Arquitectura se divulga mediante versiones digitales (PDF, HTML, XML) e impresas con un tiraje de 700 ejemplares, los tiempos de producción de estas versiones dependerán de los cronogramas establecidos por la editorial.

Los tiempos de recepción-revisión-aceptación pueden tardar entre seis y doce meses dependiendo del flujo editorial de cada sección y del proceso de revisión y edición adelantado.

Con el usuario y contraseña asignados, los autores pueden ingresar a la plataforma de gestión editorial y verificar el estado de revisión, edición o publicación del artículo.

\section{A CANJE}

La Revista de Arquitectura está interesada en establecer canje con publicaciones académicas, profesionales o científicas del área de Arquitectura y Urbanismo, como medio de reconocimiento y discusión de la producción científica en el campo de acción de la publicación.

\section{Mecanismo}

Para establecer canje por favor descargar, diligenciar y enviar el formato: RevArq FP20 Canjes

http://publicaciones.ucatolica.edu.co/revista/ arquitectura/RevArq_FP20_Canje_V2.doc

Universidad Católica de Colombia (2016, enero-junio). Revista de Arquitectura, 18(1), $1-144$.

ISSN: 1657-0308 E-ISSN: 2357-626X

Especificaciones:

Formato: $34 \times 24 \mathrm{~cm}$

Papel: Mate $115 \mathrm{~g}$

Tintas: Negro y policromía

\section{A CONTACTO}

DIRECCIÓN POSTAL:

Avenida Caracas No. 46-72. Universidad Católica de

Colombia. Bogotá D.C.(Colombia)

Código postal: 111311

Facultad de Diseño, Centro de Investigaciones (CIFAR). Sede El Claustro. Bloque "L", 4 piso, Diag. 46를. No. 15b-10. Editor, Arq. César Andrés Eligio Triana

Teléfonos: +57 (1) 3277300 - 3277333

Ext. $3109 ; 3112$ o 5146

Fax: +57 (1) 2858895

CORREO ELECTRÓNICO:

revistadearquitectura@ucatolica.edu.co cifar@ucatolica.edu.co

PÁGINA WEB:

www.ucatolica.edu.co vínculo Revistas científicas http://publicaciones.ucatolica.edu.co/revistas-cientificas http://editorial.ucatolica.edu.co/ojsucatolica/revistas_ucatolica/index.php/RevArq 
UNIVERSIDAD CATÓLICA DE COLOMBIA

PRESIDENTE

Édgar Gómez Betancourt

VICEPRESIDENTE - RECTOR

Francisco José Gómez Ortiz

VICERRECTOR JURÍDICO Y DEL MEDIO

UNIVERSITARIO

Edwin de Jesús Horta Vásquez

VICERRECTOR ADMINISTRATIVO

Édgar Gómez Ortiz

DECANO ACADÉMICO

Elvers Medellín Lozano

DIRECTORA DE INVESTIGACIONES

Elisa Urbina Sánchez

DIRECTORA EDITORIAL

Stella Valbuena García

\section{FACULTAD DE DISEÑO}

DECANO

Werner Gómez Benítez

DIRECTOR DE DOCENCIA

Jorge Gutiérrez Martínez

DIRECTOR DE EXTENSIÓN

Adriana Pedraza Pacheco

DIRECTOR DE INVESTIGACIÓN

Hernando Verdugo Reyes

DIRECTOR DE GESTIÓN DE CALIDAD

Augusto Forero La Rotta

COMITÉ ASESOR EXTERNO

FACUlTAD DE DisEÑo

Alberto Miani Uribe

Giovanni Ferroni Del Valle

Samuel Ricardo Vélez

Lorenzo Castro

FACULTAD DE DISEÑO

REVISTA DE ACCESO ABIERTO,

ARBITRADA E INDEXADA

Publindex Categoría B. Índice Bibliográfico Nacional

IBN. Colombia.

Redalyc. Red de Revistas Científicas de América Latina

y el Caribe, España y Portugal. Sistema de Información

Científica. México.

Proquest. ProQuest Research LibraryProQuest

Research Library ProQuest Research Library. Estados

Unidos

Ebsco. EBSCOhost Research Databases. Estados

Unidos.

Latindex. Sistema Regional de Información en Línea

para Revistas Científicas de América Latina, el Caribe,

España y Portugal (Directorio y catálogo). México.

Clase. Base de datos bibliográfica de revistas de cien-

cias sociales y humanidades. Universidad Autónoma

México.

Dialnet. Fundación Dialnet - Biblioteca de la Universi-

dad de La Rioja. España.

Actualidad Iberoamericana. (Índice de Revistas) Centro de Información Tecnológica (CIT). Chile.

Arla. Asociación de revistas latinoamericanas de arquitectura.

EDITORIAL

Av. Caracas No 46-72, piso 5

Teléfono: 3277300 Ext. 5145

editorial@ucatolica.edu.co

www.ucatolica.edu.co

http://publicaciones.ucatolica.edu.co/

IMPRESIÓN:

ESCALA Taller Litográfico

Calle 30 № 17-52 - (057 I) 2320482

Abril de 2016

\section{REVISTA DE ARQUITECTURA}

DIRECTOR

Werner Gómez Benítez

EDITOR

César Andrés Eligio Triana

EDITOR DE SECCIÓN

Carolina Rodríguez Ahumada

CONSEJO EDITORIAL

Werner Gómez Benítez

Jorge Gutiérrez Martínez

César Andrés Eligio Triana

Hernando Verdugo Reyes

\section{EQUIPO EDITORIAL}

COORDINADORA EDITORIAL

María Paula Godoy Casasbuenas mpgodoy@ucatolica.edu.co

DiseÑo Y MONTAJE

Juanita Isaza

juanaisaza@gmail.com

TRADUCTORES

INGLÉS

Massayel Cuéllar Hernández

massacuellar@gmail.com

CORRECTORA DE ESTILO

María José Díaz Granados M.

mariajose_dgm@yahoo.com.co

PÁGINA WEB

Centro de investigaciones (CIFAR)

DISTRIBUCIÓN Y CANJES

Claudia Álvarez Duquino

calvarez@ucatolica.edu.co
COMITÉ EDITORIAL Y CIENTÍFICO Cultura Y ESPACIO URBANO

Carlos Mario Yory, PhD

Universidad Católica de Colombia. Bogotá, Colombia

Sonia Berjman, $\mathrm{PhD}$

ICOMOS-IFLA, Buenos Aires, Argentina

Juan Carlos Pérgolis, MSc Universidad Piloto de Colombia. Bogotá, Colombia

Beatriz García Moreno, PhD

Universidad Nacional de Colombia. Bogotá, Colombia

Javier Peinado Pontón, Msc

Pontificia Universidad Javeriana. Bogotá, Colombia

Proyecto arquitectónico y URBano

Jean-Philippe Garric, PhD, HDR

Université Paris I Panthéon-Sorbonne. Paris, Francia

Debora Domingo Calabuig, $\mathrm{PhD}$

Universidad Politécnica de Valencia, España

Hugo Mondragón López, PhD

Pontificia Universidad Católica de Chile. Santiago, Chile

Germán Darío Correal Pachón, MSc Universidad Católica de Colombia. Bogotá, Colombia

Juan Pablo Duque Cañas, PhD

Universidad Nacional de Colombia. Bogotá, Colombia

Jorge Grané del Castillo, MSc Universidad de Costa Rica. San José, Costa Rica

\section{TECNOLOGÍA, MEDIOAMBIENTE Y SOSTENIBILIDAD}

Mariano Vázquez Espí, PhD.

Universidad Politéencica de Madrid, España.

Luis Carlos Herrera Sosa, PhD

Universidad Autónoma de Ciudad Juárez, México

Claudio Varini, PhD

Universidad Católica de Colombia. Bogotá, Colombia

Luis Gabriel Gómez Azpeitia, PhD Universidad de Colima. Colima, México 


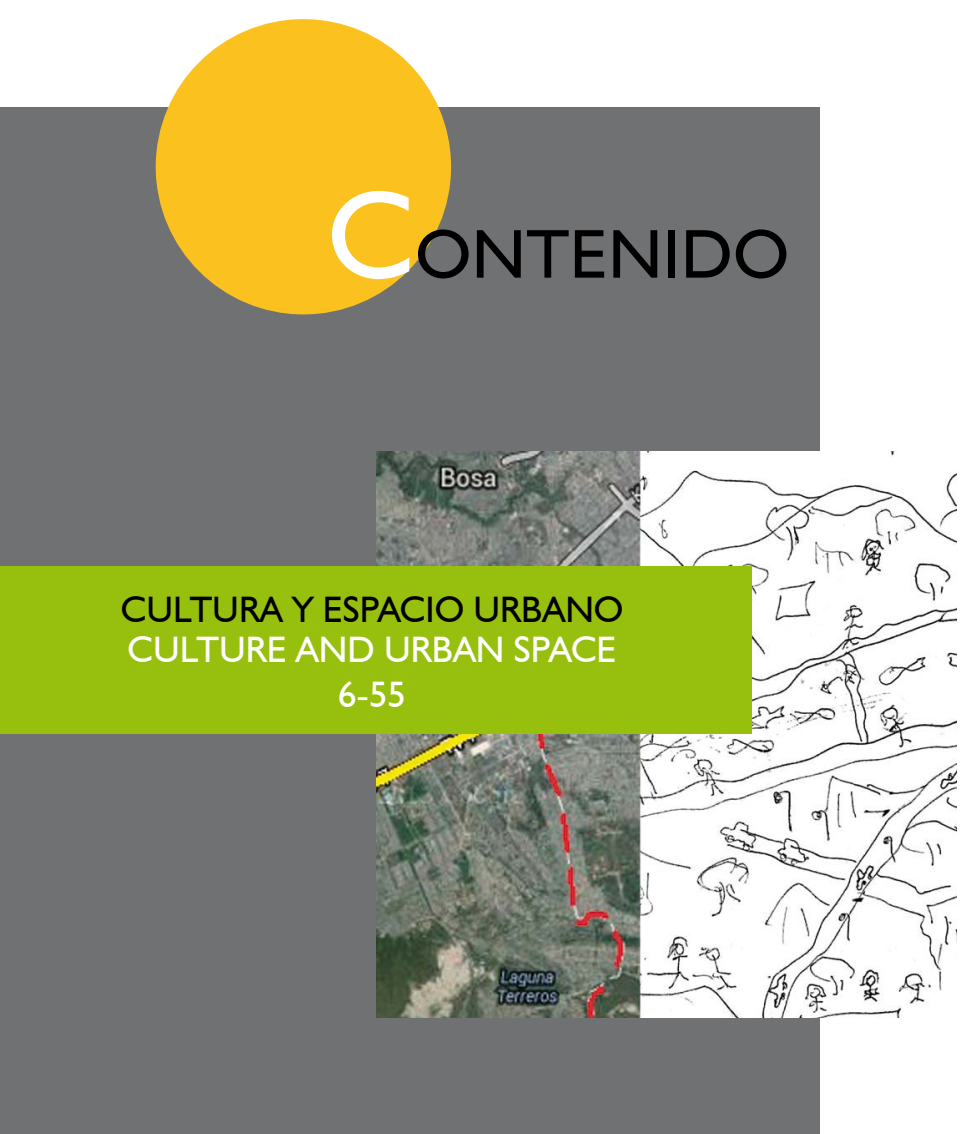

URBANISMO PARTICIPATIVO

CONSTRUCCIÓN SOCIAL DEL ESPACIO URBANO

MARY JOHANA HERNÁNDEZ ARAQUE

LA REPRESENTACIÓN SOCIAL DEL ESPACIO PÚBLICO PARA EL DISEÑO Y LA GESTIÓN DE TERRITORIOS SOSTENIBLES

UNA PROPUESTA TEÓRICO-PRÁCTICA Y METODOLÓGICA PARA UN URBANISMO PARTICIPATIVO

HeIDI NATALIE CONTRERAS-LOVICH

PROPUESTA DE UN SISTEMA DE INDICADORES PARA EVALUAR LA CALIDAD VISUAL DEL PAISAJE URBANO EN ASENTAMIENTOS INFORMALES

JOHANA ANDREA MESA CARRANZA, OSWALDO LÓPEZ BERNAL, ADRIANA PATRICIA LÓPEZ VALENCIA

\section{SEGREGACIÓN EN EL ESPACIO URBANO DE SOACHA}

¿TRANSMILENIO COMO HERRAMIENTA INTEGRADORA?

CARLOS AUGUSTO MORENO-LUNA

ARQUITETURA E INDUSTRIALIZAÇÃO DAS

CONSTRUÇÕES NA OBRA DE JOÃO FILGUEIRAS

LIMA - LELE

ELZA-LULI MIYASAKA, MARIELI LUKIANTCHUKI,

Michele C. B. Ferrari CaiXeta, Marcio-Minto Fabrício PÁg. 56

EL DISEÑO DE LA VIVIENDA DE INTERÉS SOCIAL

LA SATISFACCIÓN DE LAS NECESIDADES Y EXPECTATIVAS DEL USUARIO

ALEX LEANDRo PÉREZ-PÉREZ

\section{EXPLORACIONES MORFOLÓGICAS EN TEXTURAS} MODULARES

APROXIMACIONES DESDE EL OBIET TROUVÉ

AL DISEÑO PARAMÉTRICO

OMAR CAÑETE-ISLAS

TECNOLOGÍA, MEDIOAMBIENTE Y SOSTENIBILIDAD

TECHINOLOGY, ENVIRONMENT AND SUSTAINABILITY $76-125$
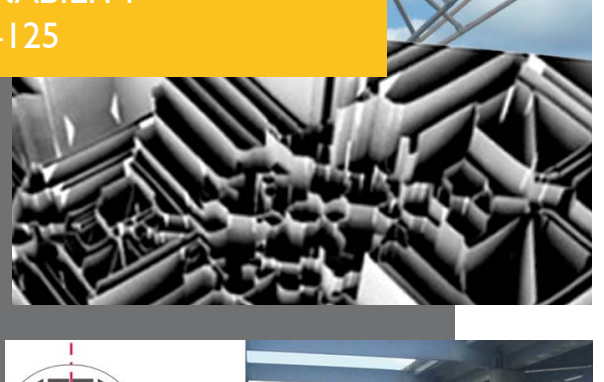

DESDE LA FACULTAD

FROM THE FACULTY 126-139

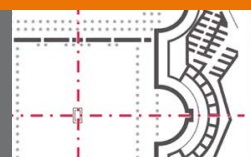

TEXTOS

TEXTS

I40-142
CONSTRUCCIÓN EXPERIMENTAL DE UN SISTEMA TRANSFORMABLE TENSADO PLEGABLE

CARLOS CÉSAR MORALES GUZMÁN

\section{LA SIMULACIÓN COMO HERRAMIENTA DE} DISEÑO Y EVALUACIÓN ARQUITECTÓNICA

PAUTAS RESUELTAS DESDE LA INGENIERÍA

JOHANNA TRUJILLO, ROLANDO ARTURO CUBILLOS-GONZÁLEZ

LAS RELACIONES ENTRE LA MOVILIDAD

Y EL ESPACIO PÚBLICO

TRANSMILENIO EN BOGOTÁ

Myriam STELLA Díaz-OSORIO, JuLIO CÉSAR MARRoQuíN

APRENDIZAJE, COMPOSICIÓN Y EMPLAZAMIENTO EN EL PROYECTO DE ARQUITECTURA [REVISIÓN DE LIBRO]

JUAN CARLOS PÉRGOLIS

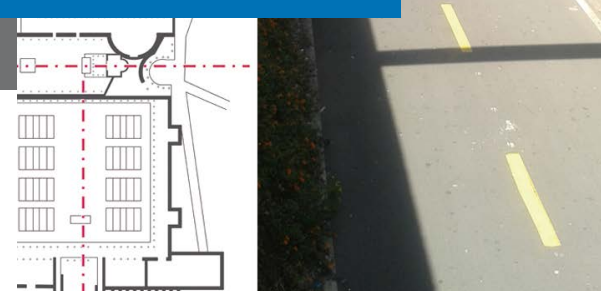




\title{
APRENDIZAJE, COMPOSICIÓN Y EMPLAZAMIENTO EN EL PROYECTO DE ARQUITECTURA [REVISIÓN DE LIBRO]
}

\author{
Juan Carlos Pérgolis
}

Pérgolis, J.C. (2016). Aprendizaje, composición y emplazamiento en el proyecto de arquitectura. [Revisión de libro Aprendizaje, composición y emplazamiento en el proyecto de arquitectura. Un diálogo entre las aproximaciones analógica y tipológica, por G. D. Correal Pachón et al. (2016)]. Revista de Arquitectura, 18(I), 140-142. doi: 10.14718/RevArq.2016.18.I.I2

\author{
Arquitecto, Universidad de la Plata (UNLP), Argentina.Magíster \\ en Teoría e Historia de la Arquitectura, Universidad Nacional de \\ Colombia. \\ Docente de historia y teoría y temas relacionados con ciudad en \\ cursos de pregrado y posgrado en universidades nacionales e inter- \\ nacionales. \\ Autor de diversos libros y artículos sobre historia y ciudad. \\ pergolisjuancarlos@yahoo.com
}

Todo libro es una prolongación del autor y, en este caso, es la prolongación de dos grupos de investigación formados por gente muy valiosa, como investigadores, amigos muy queridos $y$, también, por las personas que creo que son los más profundos conocedores de los procesos del diseño arquitectónico.

Un libro escrito a siete manos, a dos grupos y a dos instituciones que se acercan en el concepto de competencias y se alejan en la perspectiva de observación: tipológica en el caso de la Universidad Católica de Colombia y analógica en la Universidad Piloto de Colombia.

Pero lo lograron, e hicieron un texto de gran unidad sin perder los diferentes enfoques, el resultado de una correcta coordinación de investigación y un claro objetivo. Ese es — consideroel mérito más grande de este trabajo, mérito de los investigadores basado en su enorme patrimonio de conocimientos y experiencia, pero sobre todo, su gran cultura, porque no se puede hablar de arquitectura ni señalar sus procesos de diseño desde la planicie: hablar de arquitectura implica revolver entre mil rasgos de la cultura, de la gran cultura y de la popular; conocer e interpretar —el gran aporte del psicoanálisis en el siglo $x x$ - ; relacionar obras, sucesos, hechos y nombres, todo en imágenes únicas. Tal vez, ese gran mérito que cité hace un momento sea el resultado de esa capacidad de interpretar, como para diseñar, criticar o cualquier aproximación a la arquitectura. Varios puntos del libro evidencian ese bagaje, quisiera señalarlos:

En el apartado "Aprender a mirar" se cita con insistencia a Rudolf Arnheim, un psicólogo heredero de aquellos maestros de la escuela de Graz, que dieron forma - a principios del siglo XX-a la psicología fenomenológica de la percepción. Los autores lo referencian junto a Paul Rudolph y a Mies, una trilogía moderna que rara vez reunimos, pero que cuando se encuentran - como en este capítulo del libro-, nos abren un panorama que intuíamos pero no evidenciábamos. También se cita a Norberg Schulz: "aprendemos a mirar, pero debemos aprender a 'ver' el significado de las cosas...". No en vano, los psicólogos de principios del XX diferenciaban las palabras forme, es decir forma y gestalt, la forma signifi- 
cativa. Así transcurre este trabajo, entre encuentros, referencias y asociaciones entre autores que sorprendentemente tienen más coincidencias de las que sospechábamos.

Pero volvamos a Norberg Schulz, que concluye: "hace falta que la gente aprenda a ver si queremos aumentar el respeto por la arquitectura"; yo quitaría "la arquitectura", y diría: "hace falta que la gente aprenda a ver si queremos aumentar el respeto...", sin olvidar que la percepción es el primer paso en el proceso de conocimiento.

Quizás los autores tenían presente, sin asumirlo, que el respeto surge de la nitidez de la imagen y que esta se forma cuando algún estímulo externo toca una percepción que guardamos en el inconsciente. Hacer arquitectura es crear esos estímulos exteriores, pero es, a la vez, producir esas percepciones que se atesoran en el inconsciente. Sí, sin dudas, todo se inicia con la percepción; por eso vale la pena, entonces, leer y releer varias veces este capítulo que nos hace reflexionar sobre lo que vemos y sobre lo que dejamos pasar.

Luego, allí mismo, Germán Darío hace unas consideraciones pedagógicas que apuntan al aprendizaje del proyecto. Hace muchos años, tal vez más de veinte, que oigo hablar de esto a Germán y siempre dije: —ah, debí copiar eso que dijo. Por eso, ahora me encanta leerlo: más claro y más explícito que cualquier apunte que hubiera tomado de sus conceptos. Germán cita a Biggé: "el aprendizaje es una manera de provocar cambios duraderos en las personas [...] por eso la necesidad docente de forjar procesos de transformación en los individuos".

El aprendizaje es la manera como adquirimos habilidades y destrezas. Germán, que lo dijo tantas veces, no se imagina lo hondo que calaron sus palabras en los programas de las universidades, hoy todos hablamos de competencias, de lo que nos compete, y nos hizo comprender que todo proceso educativo se centra en el aprendizaje, porque la competencia es "el saber hacer en contexto".

Muchas veces hicimos transferencias de conceptos de entre la filosofía, la lingüística, la semiótica y la arquitectura. Kant habló de enunciados sintéticos y analíticos. Rafael Francesconi intenta pasar esos conceptos a los productos de nuestra profesión y habla — con acierto- de objetos arquitectónicos monolíticos y descomponibles, vistos en el contexto en que Martí Arís lo señala, como confrontación entre la arquitectura tradicional y la moderna: monolítica, de una pieza, la primera, y descomponible, la moderna, indaga sobre este rasgo de la arquitectura. Inducir a los estudiantes a reflexionar sobre estas particularidades en sus observaciones, en sus proyectos, abre el pensamiento al concepto de "tipo", es decir, una arquitectura de principios permanentes, más allá de sus singularidades.

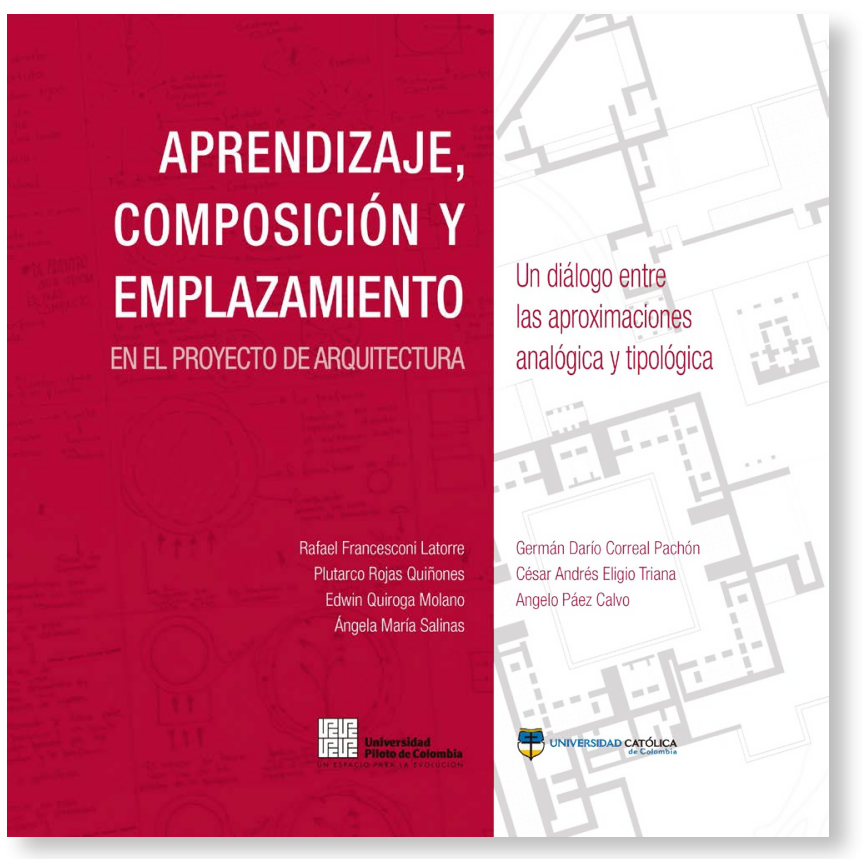

Mirar y reflexionar sobre lo que se hace... porque más que una práctica, más que una ejercitación, hacer arquitectura es zambullirse en el agitado mar de la cultura.

Preguntas: ¿cómo juega un tipo en el contexto? ¿Hay una relación entre el empleo de "tipos" y el espíritu del tiempo? Claustros, patios, bloques sueltos... ¿qué significó un tipo en la historia? No hay nada más triste en la arquitectura que ver un proyecto que toma una forma porque sí, sin saber de dónde viene y hacia dónde apunta. Nadie confiaría en una arquitectura sin raíces y sin futuro, por eso, la arquitectura no es una técnica, es un saber... y este libro lo explica muy bien.

Pero sin dudas, para los que nos formamos en los días de la arquitectura moderna, el plato fuerte del análisis aparece en la confrontación entre composición y diseño, y tampoco dudamos de que se trata de dos actitudes distintas del pensamiento ante el proceso de hacer arquitectura. Plutarco conoce la historia: el arquitecto del Renacimiento observa, representa el espacio; los posteriores lo crean. La ausencia de totalidad en las obras de los neoclásicos - agrego, pensando en Kaufmann - produjeron la independencia de las partes, basta mirar la fantástica fachada de nuestro Capitolio o recordar las maravillas de Schinkel en Berlín. Los modernos compusieron, Le Corbusier habló del "juego sabio correcto de los volúmenes bajo la luz"; más tarde, los Krier, Hans Hollein y otros, en los años ochenta, intentaron recuperar el diseño, lograr un todo, no por las partes — que pueden o no estar bajo la luz- sino por el recorrido: el museo de Hollein en Möngengladbach; una arquitectura que, como diría Machado, pasa haciendo caminos... recorre el espacio...

También César Eligio se acerca al problema de las tipologías, va más allá de la forma y habla de relaciones sociales y nos trae a Cassirer, de él César deriva una hipótesis, que todo estudiante de arquitectura debería mantener a la vista:
(A) Correal Pachón, G.D. Francesconi Latorre, $\mathrm{R}$. Rojas Quiñones, P., Eligio Triana, C.A., Quiroga Molano, E., Páez Calvo,

A., Salinas, A.M., Aprendizaje, composición y emplazamiento en el proyecto de arquitectura: diálogo entre las aproximaciones tipológica y analógica. Bogotá: Universidad Católica de Colombia y Universidad Piloto de Colombia.

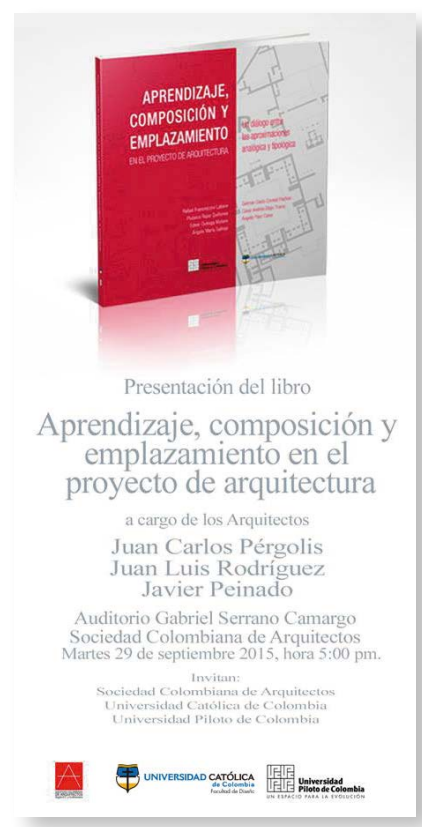

A Invitación a la presentación del libro. Evento realizado el 29 de septiembre de 2015 en el auditorio Gabriel Serrano Camargo de la Sociedad Colombiana de Arquitectos en Bogotá - Colombia. 

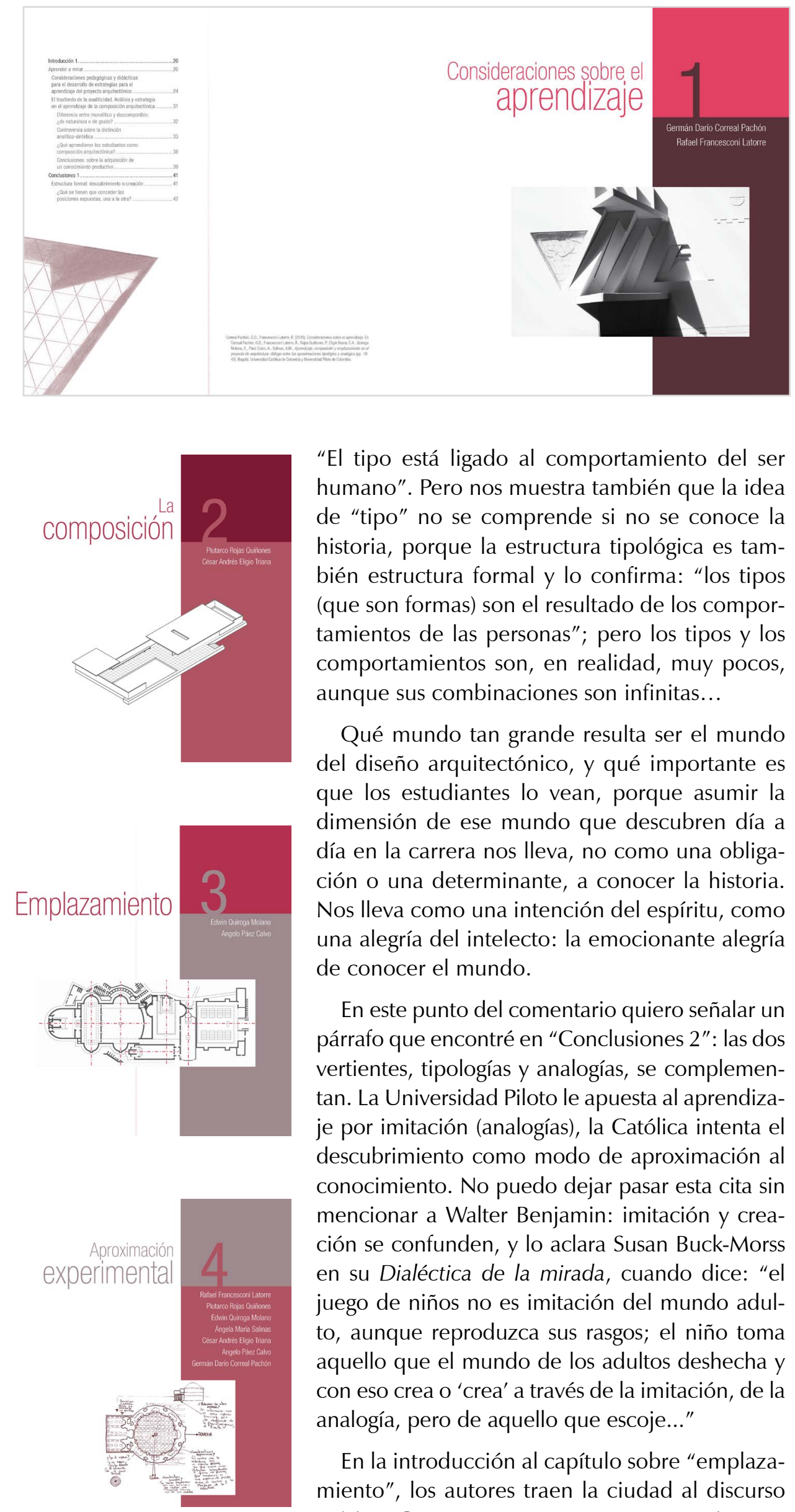

A Temas sobre los que trata cada uno de los capítulos
"El tipo está ligado al comportamiento del ser humano". Pero nos muestra también que la idea de "tipo" no se comprende si no se conoce la bién estructura formal y lo confirma: "los tipos (que son formas) son el resultado de los comportamientos de las personas"; pero los tipos y los comportamientos son, en realidad, muy pocos, aunque sus combinaciones son infinitas...

Qué mundo tan grande resulta ser el mundo del diseño arquitectónico, y qué importante es que los estudiantes lo vean, porque asumir la dimensión de ese mundo que descubren día a día en la carrera nos lleva, no como una obligación o una determinante, a conocer la historia. Nos lleva como una intención del espíritu, como una alegría del intelecto: la emocionante alegría de conocer el mundo.

En este punto del comentario quiero señalar un párrafo que encontré en "Conclusiones 2": las dos vertientes, tipologías y analogías, se complementan. La Universidad Piloto le apuesta al aprendizaje por imitación (analogías), la Católica intenta el descubrimiento como modo de aproximación al conocimiento. No puedo dejar pasar esta cita sin mencionar a Walter Benjamin: imitación y creación se confunden, y lo aclara Susan Buck-Morss en su Dialéctica de la mirada, cuando dice: "el juego de niños no es imitación del mundo adulto, aunque reproduzca sus rasgos; el niño toma aquello que el mundo de los adultos deshecha y con eso crea o 'crea' a través de la imitación, de la analogía, pero de aquello que escoje..."

En la introducción al capítulo sobre "emplazamiento", los autores traen la ciudad al discurso teórico. Creo que en este momento comienza a definirse un nuevo sentido en la investigación, en la comprensión de la arquitectura y en sus procesos de diseño: cómo se establece la relación entre la arquitectura y el sitio, y una pregunta que es fundamental y tiene una respuesta afirmativa: ¿el sitio, es la ciudad?

Solo quien conoce profundamente la historia de la arquitectura y a sus autores puede tener el acierto de comenzar esta mirada con una referenhistoria, porque la estructura tipológica es tam- cia a Carlo Giulio Argan y citar una de sus observaciones más trascendentes: "la composición surge del objeto arquitectónico, mientras que la determinación formal emerge del sitio", y observar a este desde dos aproximaciones: como una preexistencia al objeto arquitectónico y como una presencia activa determinante del objeto. Los autores logran una síntesis entre las particularidades del sitio y la arquitectura, y esta síntesis, en una investigación que se paseó por los conceptos de tipología y analogía, aclaró notablemente la intención del proceso de diseño: una posición mira al sitio como determinante del emplazamiento, otra al objeto arquitectónico como principio de composición del emplazamiento.

La transformación en el emplazamiento surge de su obvia preexistencia, pero la llamada transposición aparece al comprender que la ciudad es análoga a la arquitectura ya que ambas están compuestas por elementos, partes y relaciones, que en la arquitectura corresponden a la composición y en la ciudad dependen del emplazamiento.

Las ciudades son arquitecturas, por tanto, también son el resultado de una composición y ninguna parte puede bastarse por sí sola, todas están subordinadas a un interés general; y así, casi al final del libro, apareció la cuestión que soportó la reflexión teórica del siglo XX: la relación entre las partes y la totalidad, tratada con cuidado y precisión por los autores: para que exista música, discurso o arquitectura no basta con los elementos, se requiere una estructura, una idea general, un objetivo. De esta manera, los binomios arquitectura-composición y ciudad-emplazamiento se relacionan con factores exógenos: el sitio, la actividad, la técnica.

Sin embargo, la síntesis está enunciada en Aldo Rossi con la frase "la relación entre arquitectura y ciudad es binaria, transformación y transposición relacionan la arquitectura al emplazamiento". Pero quiero cerrar este comentario citando a Ángelo Páez, que señala que la tipología es un instrumento que valida la historia de la arquitectura.

Yo agregaría que la analogía también. Y pienso nuevamente en Walter Benjamin, en Calle de sentido único o en Infancia en Berlín... Muchas veces me he preguntado ¿cómo hacen arquitectura quienes no conocen la historia? O icómo hacen ciudades los que no conocen los trazados de Hipodamo de Mileto o los de las ciudades ideales del Renacimiento o los ejes de las ciudades neoclásicas? Por último: ¿cómo hubieran hecho esta reflexión —que es fundamental en nuestros contextos donde la profesión está cada día más cerca de una práctica técnica que de un ejercicio del intelecto- como hubieran hecho, insisto, si no conocieran la historia? Porque el conocimiento implica interpretación —otro de los rasgos del siglo $\mathrm{XX}$ - y para poder interpretar, hay que conocer. 
La postulación de un artículo a la Revista de Arquitectura indica que- el o los autores certifican que conocen y aceptan la política editorial, para lo cual firmarán en original y remitirán el formato RevArq FP00 Carta de originalidad.

La Revista de Arquitectura maneja una política de Autoarchivo VERDE, según las directrices de SHERPA/RoMEO, por lo cual el autor puede:

Pre-print del autor: Archivar la versión pre-print (la versión previa a la revisión por pares)

Post-print del autor: Archivar la versión post-print (la versión final posterior a la revisión por pares)

Versión de editor/PDF: Archivar la versión del editor - PDF/HTML/XLM en la maqueta de la Revista de Arquitectura.

El Autoarchivo se debe hacer respetando la licencia de acceso abierto, la integridad y la imagen de la Revista de Arquitectura, también se recomienda incluir la referencia, el vínculo electrónico y el DOI.

El autor o los autores son los titulares del Copyright (c) del texto publicado y la Editorial de la Revista de Arquitectura solicita la firma de una autorización de reproducción del artículo (RevArq FP03 Autorización reproducción), la cual se acoge a la licencia CC, donde se expresa el derecho de primera publicación de la obra.

La Revista de Arquitectura se guía por las normas internacionales sobre propiedad intelectual y derechos de autor, y de manera particular el artículo 58 de la Constitución Política de Colombia, la Ley 23 de 1982 y el Acuerdo 172 del 30 de septiembre de 2010 (Reglamento de propiedad intelectual de la Universidad Católica de Colombia).

Para efectos de autoría y coautoría de artículos se diferencian dos tipos: "obra en colaboración" y "obra colectiva". La primera es aquella cuya autoría corresponde a todos los participantes al ser fruto de su trabajo conjunto. En este caso, quien actúa como responsable y persona de contacto debe asegurar que quienes firman como autores han revisado y aprobado la versión final, y dan consentimiento para su divulgación. La obra colectiva es aquella en la que, aunque participan diversos colaboradores, hay un autor que toma la iniciativa, la coordinación y realización de dicha obra. En estos casos, la autoría corresponderá a dicha persona (salvo pacto en contrario) y será suficiente únicamente con su autorización de divulgación.

El número de autores por artículo debe estar justificado por el tema, la complejidad y la extensión, y no deberá ser superior a la media de la disciplina, por lo cual se recomienda que no sea mayor de cinco. El orden en que se enuncien corresponderá a los aportes de cada uno a la construcción del texto, se debe evitar la autoría ficticia o regalada. Si se incluyen más personas que trabajaron en la investigación se sugiere que sea en calidad de colaboradores o como parte de los agradecimientos. La Revista de Arquitectura respetará el número y el orden en que figuren en el original remitido. Si los autores consideran necesario, al final del artículo pueden incluir una breve descripción de los aportes individuales de cada uno de firmantes.

La comunicación se establece con uno de los autores, quien a su vez será el responsable de informar a los demás autores de las notificaciones emitidas por la Revista de Arquitectura.

En virtud de mantener el equilibro de las secciones y las mismas oportunidades para todos los participantes, un mismo autor puede postular dos o más artículos de manera simultánea; si la decisión editorial es favorable y los artículos son aceptados, su publicación se realizará en números diferentes.

\section{(A) ACCESO ABIERTO}

La Revista de Arquitectura, en su misión de divulgar la investigación y apoyar el conocimiento y la discusión en los campos de interés, proporciona acceso abierto, inmediato e irrestricto a su contenido de manera gratuita mediante la distribución de ejemplares impresos y digitales. Los interesados pueden leer, descargar, guardar, copiar y distribuir, imprimir, usar, buscar o referenciar el texto completo o parcial de los artículos o la totalidad de la Revista de Arquitectura.

\section{(c) (1) (9)}

Esta revista se acoge a la licencia Creative Commons (CC BYNC de Atribución - No comercial 4.0 Internacional): "Esta licencia permite a otros entremezclar, ajustar y construir a partir de su obra con fines no comerciales, y aunque en sus nuevas creaciones deban reconocerle su autoría y no puedan ser utilizadas de manera comercial, no tienen que estar bajo una licencia con los mismos términos".

La Revista de Arquitectura es divulgada en centros y grupos de investigación, en bibliotecas y universidades, y en las principales facultades de Arquitectura, mediante acceso abierto a la versión digital y suscripción anual al ejemplar impreso o por medio de canje, este último se formaliza mediante el formato RevArq FP20 Canjes.

Para aumentar su visibilidad y el impacto de los artículos, se envían a bases de datos y sistemas de indexación y resumen (SIR) y, asimismo, pueden ser consultados y descargados en la página web de la revista.

La Revista de Arquitectura no maneja cobros, tarifas o tasas de publicación de artículo (Article Processing Charge-APC), o por el sometimiento de textos a la publicación.

\section{(1ÉTICA Y BUENAS PRÁCTICAS}

La Revista de Arquitectura se compromete a cumplir y respetar las normas éticas en todas las etapas del proceso de publicación. Los autores de los artículos publicados darán cumplimiento a los principios éticos contenidos en las diferentes declaraciones y legislaciones sobre propiedad intelectual y derechos de autor específicos del país donde se realizó la investigación. En consecuencia, los autores de los artículos postulados y aceptados para publicar, que presentan resultados de investigación, deben firmar la declaración de originalidad (formato RevArq FP00 Carta de originalidad).

La Revista de Arquitectura reconoce y adopta los principios de transparencia y buenas prácticas descritos por COPE, "Principles of Transparency and Best Practice in Scholarly Publishing" (2015).

El equipo editorial tiene la obligación de guardar la confidencialidad acerca de los artículos recibidos, y abstenerse de usar en sus propias investigaciones datos, argumentos o interpretaciones hasta tanto el artículo no sea publicado. También debe ser imparcial y gestionar los artículos de manera adecuada y en los plazos establecidos. La selección de revisores se hará con objetividad y estos deberán responder a la temática del artículo.

El editor, los autores y los revisores deben seguir las normas éticas internacionales definidas por el Committee on Publication Ethics (COPE), con el fin de evitar casos de:

- Fabricación, falsificación u omisión de datos.

- Plagio y autoplagio.

- Publicación redundante, duplicada o fragmentada.

- Omisión de referencias a las fuentes consultadas.

- Utilización de contenidos sin permiso o sin justificación.

- Apropiación individual de autoría colectiva.

- Cambios de autoría.

- Conflicto de interés (CDI) no revelado o declarado.

- Otras que pudieran surgir en el proceso de investigación y publicación. La fabricación de resultados se genera al mostrar datos inventados por los autores; la falsificación resulta cuando los datos son manipulados y cambiados a capricho de los autores; la omisión se origina cuando los autores ocultan deliberadamente un hecho o dato. El plagio se da cuando un autor presenta como ideas propias datos creados por otros. Los casos de plagio son los siguientes: copia directa de un texto sin entrecomillar o citar la fuente, modificación de algunas palabras del texto, paráfrasis y falta de agradecimientos; el autoplagio se da cuando el mismo autor reutiliza material propio que ya fue publicado, pero sin indicar la referencia al trabajo anterior. La revista se apoya en herramientas digitales que detectan cualquiera de estos casos en los artículos postulados, y es labor de los editores y revisores velar por la originalidad y fidelidad en la citación. La publicación redundante o duplicada se refiere a la copia total, parcial o alterada de un trabajo ya publicado por el mismo autor

En caso de sospechar de alguna mala conducta se recomienda seguir los diagramas de flujo elaborados por COPE (2008), con el fin de determinar las acciones correspondientes.

La Revista de Arquitectura se reserva el derecho de retractación de publicación de aquellos artículos que, posterior a su publicación, se demuestre que presentan errores de buena fe, o cometieron fraudes o malas prácticas científicas. Esta decisión se apoyará en "Retraction Guidelines" (COPE, 2009). Si el error es menor, este se podrá rectificar mediante una nota editorial de corrección o una fe de erratas. Los autores también tienen la posibilidad de solicitar la retractación de publicación cuando descubran que su trabajo presenta errores graves. En todos los casos se conservará la versión electrónica y se harán las advertencias de forma clara e inequívoca.

\section{A PRIVACIDAD Y MANEJO DE LA INFORMACIÓN.} HABEAS DATA

Para dar cumplimiento a lo previsto en el artículo 10 del Decreto 1377 de 2013, reglamentario de la Ley 1581 de 2012, y según el Acuerdo 002 del 4 de septiembre de 2013 de la Universidad Católica de Colombia, "por el cual se aprueba el manual de políticas de tratamiento de datos personales"

La Universidad Católica de Colombia, considerada como responsable o encargada del tratamiento de datos personales, manifiesta que los datos personales de los autores, integrantes de los comités y pares revisores, se encuentran incluidos en nuestras bases de datos; por lo anterior, y en cumplimiento de las disposiciones legales vigentes, la Universidad solicitará siempre su autorización, para que en desarrollo de sus funciones propias como Institución de Educación Superior, en especial las relacionadas con la docencia, la extensión y la investigación, la Universidad Católica de Colombia pueda recolectar, recaudar, almacenar, usar, circular, suprimir, procesar, intercambiar, compilar, dar tratamiento, actualizar, transmitir o transferir a terceros países y disponer de los datos que le han suministrado y que han sido incorporados en las bases de datos de todo tipo que reposan en la Universidad.

La Universidad Católica de Colombia queda autorizada, de manera expresa e inequívoca, en los términos señalados por el Decreto 1377 de 2013, para mantener y manejar la información de nuestros colaboradores (autores, integrantes de los diferentes comités y pares revisores); así mismo, los colaboradores podrán ejercer sus derechos a conocer, actualizar, rectificar y suprimir sus datos personales, para lo cual se han dispuesto las siguientes cuentas de correo electrónico: 
La Revista de Arquitectura recibe artículos de manera permanente. Los artículos se procesan a medida que se postulan, dependiendo el flujo editorial de cada sección.

El idioma principal es el español, y como opcionales están definidos el inglés, el portugués y el francés; los textos pueden ser escritos y presentados en cualquiera de estos.

Los artículos postulados deben corresponder a las categorías universalmente aceptadas como producto de investigación, ser originales e inéditos y sus contenidos responder a criterios de precisión, claridad y brevedad.

Como punto de referencia se pueden tomar las tipologías y definiciones del Índice Bibliográfico Nacional, Publindex (2010) que se describen la continuación:

1. Artículo de revisión: documento resultado de una investigación terminada donde se analizan, sistematizan e integran los resultados de investigaciones publicadas o no publicadas, sobre un campo en ciencia o tecnología, con el fin de dar cuenta de los avances y las tendencias de desarrollo. Se caracteriza por presentar una cuidadosa revisión

bibliográfica de por lo menos 50 referencias.
2. Artículo de investigación científica y tecnológica: documento que presenta, de manera detallada, los resultados originales de proyectos terminados de investigación. La estructura generalmente utilizada contiene cuatro apartes importantes: introducción, metodología, resultados y conclusiones.

3. Artículo de reflexión: documento que presenta resultados de investigación terminada desde una perspectiva analítica, interpretativa o crítica del autor, sobre un tema específico, recurriendo a fuentes originales.

En todos los casos se debe presentar la información suficiente para que cualquier investigador pueda reproducir la investigación y confirmar o refutar las interpretaciones defendidas.

También se pueden presentar otro tipo de documentos diferentes a los anteriormente descritos, como pueden ser: artículo corto, reporte de caso, revisión de tema, documento resultado de la revisión crítica de la literatura sobre un tema en particular, cartas al editor, traducción, documento de reflexión no derivado de investigación, reseña bibliográfica, así como proyectos de arquitectura o urbanismo, entre otros

\section{A INSTRUCCIONES PARA POSTULAR ARTÍCULOS}

Postular el artículo en la página web de la Revista de Arquitectura y adjuntar comunicación escrita dirigida al editor RevArq_FP00 Carta de originalidad (debidamente firmada por todos los autores en original); de igual manera, se debe diligenciar el formato de hoja de vida RevArq FP01 Hoja de Vida (una por cada autor).

En la comunicación escrita el autor expresa que conoce y acepta la política editorial de la Revista de Arquitectura, que el artículo no está postulado para publicación simultáneamente en otras revistas u órganos editoriales y que no existe conflicto de intereses (ver modelo RevArq FP06 CDI) y que, de ser aceptado, concederá permiso de primera publicación, no exclusiva a nombre de la Universidad Católica de Colombia como editora de la revista.

Los artículos deben tener en cuenta las siguientes recomendaciones:

- En la primera página del documento se debe incluir:

TítUlo: no exceder 15 palabras.

Subtítulo: opcional, complementa el título o indica las principales subdivisiones del texto.

NOMBRE DEL AUTOR O AUTORES: nombres y apellidos completos o según modelo de citación adoptado por el autor para la normalización de los nombres del investigador. Como nota al pie (máximo 150 palabras): formación académica, experiencia profesional e investigativa, vinculación laboral, premios o reconocimientos, publicaciones representativas e información de contacto, correo electrónico.

FILIACIÓN INSTITUCIONAL: debajo del nombre se debe declarar la inV titución en la cual se desarrolló el producto, de la cual recibió apoyo o aquella que respalda el trabajo investigativo.

RESUMEN: debe ser analítico, se redacta en un solo párrafo, da cuenta del tema, el objetivo, la metodología, los resultados y las conclusiones; no debe exceder las 150 palabras.

PALABRAS CLAVE: cinco palabras o grupo de palabras, ordenadas alfabéticamente y que no se encuentren en el título o subtítulo; estas sirven para clasificar temáticamente al artículo. Se recomienda emplear principalmente palabras definidas en el tesauro de la Unesco (http:// databases.unesco.org/thessp/) o en el tesauro de Arte \& Arquitectura (C) (www.aatespanol.cl).

También se recomienda incluir título, resumen y palabras clave en segundo idioma.

- La segunda página y siguientes deben tener en cuenta:

El cuerpo del artículo generalmente se divide en: Introducción, Metodología, Desarrollo, Resultados y Discusión de resultados; posteriormente se presentan las Conclusiones, y luego las Referencias bibliográficas y los Anexos (método IMRYD). Las tablas y figuras se deben incorporar en el texto.

DESCRIPCIÓN DEL PROYECTO DE INVESTIGACIÓN: en la introducción se debe describir el tipo de artículo y brevemente el marco investigativo del cual es resultado y diligenciar el formato (RevArq FP02 Info Proyectos de Investigación).

TEXTO: todas las páginas deben venir numeradas y con el título de artículo en la parte inferior (pie de página). Márgenes de $3 \mathrm{~cm}$ por todos los lados, interlineado doble, fuente Arial o Times New Roman de 12 puntos, texto justificado (Ver plantilla para presentación de artículos). La extensión de los artículos debe ser de alrededor de 5.000 palabras ( \pm 20 páginas, incluyendo gráficos, tablas, referencias, etc.); como mínimo 3.500 y máximo 8.000 palabras. Se debe seguir el estilo vigente y recomendado en el Manual para Publicación de la American Psychological Association (APA). (Para mayor información véase http://www.apastyle.org/)
CITAS Y NOTAS AL PIE: las notas aclaratorias o notas al pie no deben exceder cinco líneas o 40 palabras, de lo contrario estas deben ser incorporadas al texto general. Las citas pueden ser:

Corta: (con menos de 40 palabras) se incorporan al texto y pueden ser: textuales (se encierran entre dobles comillas), parafraseo o resumen (se escriben en palabras del autor dentro del texto).

Cita textual extensa: (mayor de 40 palabras) debe ser dispuesta en un renglón y un bloque independiente con sangrías y omitiendo las comillas, no olvidar en ningún caso la referencia del autor (Apellido, año, página).

REFERENCIAS: como modelo para la construcción de referencias se emplea el estilo recomendado en el Manual para Publicación de la American Psychological Association (APA) (http://www.apastyle.org/).

SIGLAS: en caso de emplear siglas en el texto, las figuras o las tablas, se debe proporcionar la equivalencia completa la primera vez que se empleen y encerrarlas entre paréntesis. En el caso de citar personajes reconocidos se deben colocar nombres o apellidos completos, nunca emplear abreviaturas.

GRÁFICOS Y TABLAS: las figuras (gráficos, diagramas, ilustraciones, planos, mapas o fotografías) y las tablas deben ir numeradas y contene título o leyenda explicativa relacionada con el tema del artículo, que no exceda las 15 palabras (Figura 1. xxxxx, Tabla 1. xxxx, etc.) y la procedencia (fuente: autor o fuente, año, página). Estas se deben citar en e texto de forma directa o entre paréntesis; se recomienda hacerlo con referencias cruzadas.

También se deben entregar en medio digital, independiente del texto, en formatos editables o abiertos. La marcación de los archivos debe corresponder a la incluida en el texto. Según la extensión del artículo se deben incluir de 5 a 10 gráficos. Ver guía para la búsqueda de imágenes de dominio público o bajo licencias Creative Commons (CC).

El autor es el responsable de adquirir los derechos o las autorizaciones de reproducción a que haya lugar para imágenes o gráficos tomados de otras fuentes, así como de entrevistas o material generado por colaboradores diferentes a los autores; de igual manera, se debe garantizar la protección de datos e identidades para los casos que sea necesario.

FOTOGRAFíA: pueden ser entregadas en original para ser digitalizadas, de lo contrario se deben digitalizar con una resolución igual o superior a 300 dpi para imágenes a color y 600 para escala de grises. Los formatos de las imágenes pueden ser TIFF, PSD o JPG, y deben cumplir con las características expresadas en el punto anterior (gráficos).

PLANIMETRÍA: se debe entregar la planimetría original en medio digital en lo posible en formato CAD, y sus respectivos archivos de plumas o en PDF; de no ser posible, se deben hacer impresiones en tamaño carta con las referencias de los espacios mediante numeración y lista adjunta. Deben tener escala gráfica, escala numérica, norte, coordenadas y localización. En lo posible, no deben contener textos, achurados o tramas.

Para más detalles, consultar el documento RevArq Parámetros para Autores Descripción en el portal web de la Revista de Arquitectura

\section{Beneficios}

Como reconocimiento a los autores, se les hará envío postal de dos ejemplares de la edición impresa sin ningún costo y entregada en la dirección consignada en el formato de hoja de vida (RevArq FP01); adicionalmente, se enviará el vínculo para la descarga de la versión digital.

También se enviará una constancia informativa en la que se relaciona la publicación del artículo y, de manera opcional, se pueden detallar las fechas del proceso editorial y el arbitraje realizado. 
La selección de revisores se realiza de acuerdo con los siguientes criterios:

- Afinidad temática.

- Formación académica.

- Experiencia investigativa y profesional.

- Producción editorial en revistas similares o en libros resultado de investigación.

El proceso de arbitraje se basa en los principios de equidad e imparcialidad, y en los criterios de calidad y pertinencia.

El desarrollo de la revisión se realiza según el formato (RevArq FP10 Evaluación de artículos) y las observaciones que el revisor considere necesarias en el cuerpo del artículo. En cualquiera de los conceptos que emita el revisor (Aceptar, Publicable con modificaciones, Reevaluable o No publicable), y como parte de la labor formativa y de comunidad académica, el revisor hará sugerencias para mejorar el documento. El revisor podrá solicitar una nueva relectura del artículo después de los ajustes realizados por el autor.

El revisor también deberá diligenciar el formato RevArq FP01 Hoja de Vida, con el fin de certificar y soportar el proceso de revisión ante los SIR que así lo soliciten.

En el proceso de arbitraje se emplea el método doble ciego, los nombres del revisor no serán conocidos por el autor y viceversa. Con el fin de garantizar el anonimato del autor, al artículo postulado se le han podido suprimir nombres, instituciones o imágenes que puedan ser asociadas de manera directa al autor.

Aunque se procura el anonimato, una vez recibida la invitación como par revisor del artículo, el revisor debe cerciorarse de que no exista conflicto de intereses (CDI) o alguna limitante que afecte la revisión o que pueda ser vista como tal (lazos familiares, amistad o enemistad, vínculos contractuales o laborales, posiciones éticas, etc.), de presentarse esta situación se notificara al editor. (Ver modelo RevArq FP06 CDI).

Dada la confidencialidad del proceso de revisión, y considerando los derechos de autor y de propiedad intelectual que pueda haber sobre el material que se entrega, el revisor se compromete a mantener en absoluta reserva su labor, a limitar el uso de la obra entregada solo para el propósito designado y a devolver la documentación remitida una vez concluya la actividad.

El tiempo establecido para las revisiones de pares es de máximo un mes a partir de la confirmación de la recepción de la documentación. Ese plazo podrá ser modificado de mutuo acuerdo entre el editor y el revisor, siempre y cuando no afecte la periodicidad de la revista, la impresión o el tiempo para emitir una respuesta al autor. Los revisores se acogerán a "COPE Ethical Guidelines for Peer Reviewers" de COPE.

\section{Beneficios}

Como retribución a los revisores se les hará envío postal de un ejemplar de la edición impresa sin ningún costo y entregada en la dirección consignada en el formato de hoja de vida. También, si es de interés para el revisor, podrá hacer la solicitud de alguna de las publicaciones editadas y presentes en el catálogo de publicaciones de la UNIVERSIDAD Católica de Colombia, previa aprobación de la Editorial y sujeto a la disponibilidad.

Si lo desea tendrá derecho a una constancia de la colaboración en la revisión de artículos, la cual solo contendrá el periodo en el cual se realizó la actividad. También tendrá la posibilidad de aceptar o no la publicación de su nombre, nacionalidad y nivel máximo de formación en la página web de la Revista de Arquitectura en su calidad de colaborador.

\section{(A) PROCESO DE REVISIÓN POR PARES}

Luego de la postulación del artículo, el editor de la Revista de Arquitectura selecciona y clasifica los artículos que cumplen con los requisitos establecidos en las directrices para los autores. El editor podrá rechazar en primera instancia artículos, sin recurrir a un proceso de revisión, si los considera de baja calidad o por presentar evidencias de faltas éticas o documentación incompleta.

Los artículos se someterán a un primer dictamen del editor, de los editores de sección y del Comité Editorial, teniendo en cuenta:

- Afinidad temática, relevancia del tema y correspondencia con las secciones definidas.

- Respaldo investigativo.

- Coherencia en el desarrollo del artículo, así como una correcta redacción y ortografía.
- Relación entre las figuras y tablas con el texto del artículo.

En esta revisión se verificará el nivel de originalidad mediante el uso de software especializado (Ithenticate o similar) y recursos digitales existentes para tal fin, también se observará la coherencia y claridad en los apartados del documento (método IMRYD), la calidad de las fuentes y la adecuada citación, esto quedará consignado en el formato (RevArq FP09 Revisión de artículos); esta información será cargada a la plataforma de gestión editorial y estará a disposición del autor.

En caso de que el artículo requiera ajustes preliminares, será devuelto al autor antes de ser remitido a revisores. En este caso, el autor tendrá veinte días para remitir nuevamente el texto con los ajustes solicitados.

Después de la preselección se asignan mínimo dos revisores especializados, quienes emitirán su concepto utilizando el formato (RevArq FP10 Evaluación de artículos) y las anotaciones que consideren oportunas en el texto; en esta etapa se garantizará la confidencialidad y el anonimato de autores y revisores (modalidad doble ciego).

Del proceso de revisión se emite uno de los siguientes conceptos que será reportado al autor:

- Aceptar el envío: con o sin observaciones.

- Publicable con modificaciones: se podrá sugerir la forma más adecuada para una nueva presentación, el autor puede o no aceptar las observaciones según sus argumentos. Si las acepta, cuenta con quince días para realizar los ajustes pertinentes.

- Reevaluable: cumple con algunos criterios y debe ser corregido. Es necesario hacer modificaciones puntuales y estructurales al artículo. En este caso, el revisor puede aceptar o rechazar hacer una nueva lectura del artículo luego de ajustado.

- No publicable: el autor puede volver a postular el artículo e iniciar nuevamente el proceso de arbitraje, siempre y cuando se evidencien los ajustes correspondientes.

En el caso de presentarse diferencias sustanciales y contradictorias en los conceptos sobre la recomendación del revisor, el editor remitirá el artículo a un revisor más o a un miembro del Comité Editorial quien podrá actuar como tercer árbitro, con el fin de tomar una decisión editorial sobre la publicación del artículo.

Los autores deberán considerar las observaciones de los revisores o de los editores, y cada corrección incorporada u omitida debe quedar justificada en el texto o en una comunicación adjunta. En el caso que los autores omitan las indicaciones realizadas sin una argumentación adecuada, el artículo será devuelto y no se dará por recibido hasta que no exista claridad al respecto.

El editor respetará la independencia intelectual de los autores y a estos se les brindará el derecho de réplica en caso de que los artículos hayan sido evaluados negativamente y rechazados.

Los autores, con su usuario y contraseña, podrán ingresar a la plataforma de Gestión Editorial, donde encontrarán los conceptos emitidos y la decisión editorial sobre el artículo.

El editor y el Comité Editorial se reservan el derecho de aceptar o no la publicación del material recibido. También se reservan el derecho de sugerir modificaciones de forma, ajustar las palabras clave o el resumen y de realizar la corrección de estilo. El autor conocerá la versión final del texto antes de la publicación oficial del mismo.

Cuando un artículo es aceptado para su publicación, el auto debe firmar la autorización de reproducción (RevArq FP03 Autorización reproducción). Para más información ver: Política de derechos de autor

\section{Notas aclaratorias:}

La Revista de Arquitectura publica un número limitado de artículos por volumen y busca el equilibrio entre las secciones, motivo por el cual, aunque un artículo sea aceptado o continúe en proceso de revisión, podrá quedar aplazado para ser publicado en un próximo número; en este caso, el autor estará en la posibilidad de retirar la postulación del artículo o de incluirlo en el banco de artículos del próximo número.

El editor y los editores de sección de la Revista de Arquitectura son los encargados de establecer contacto entre los autores y revisores, ya que estos procesos se realizan de manera anónima.

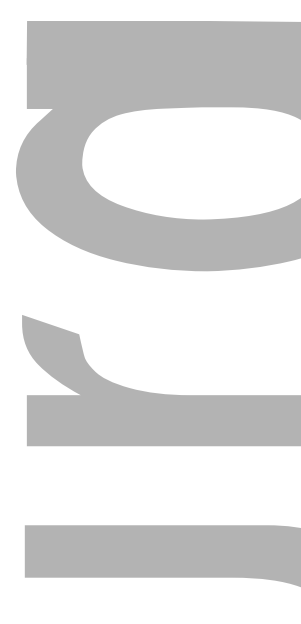

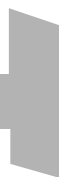
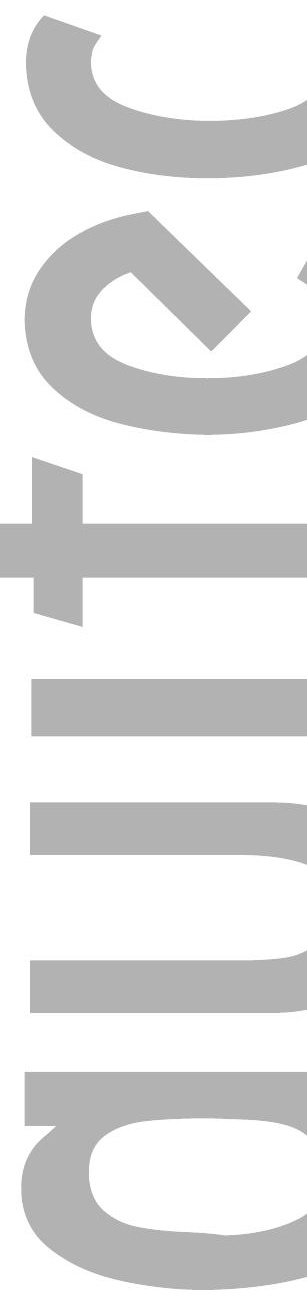

(2)

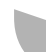

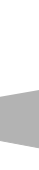

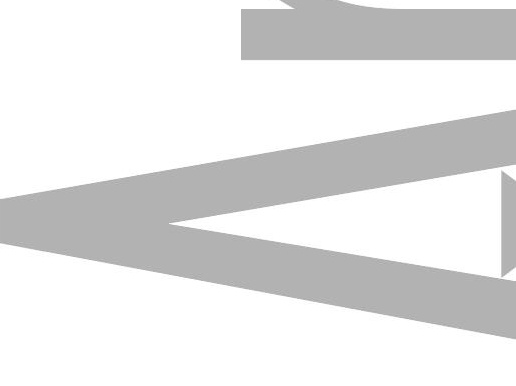


THE SOCIAL REPRESENTATION OF PUBLIC SPACE FOR THE DESIGN AND

MANAGEMENT OF SUSTAINABLE TERRITORIES

A THEORETICAL-PRACTICAL AND METHODOLOGICAL PROPOSAL FOR

PARTICIPATORY PLANNING

\section{Heidi Natalie Contreras-Lovich}

\section{PROPUESTA DE UN SISTEMA DE INDICADORES PARA EVALUAR}

PROPOSAL FOR A SYSTEM OF INDICATORS TO ASSESS THE VISUAL QUALITY OF

THE URBAN LANDSCAPE IN INFORMAL SETTLEMENTS

Johana Andrea Mesa Carranza, OsWaldo López Bernal.

Adriana Patricia López Valencia

Segregación EN EL ESPACIO URBANO de SOACHA

¿TRANSMILENIO COMO HERRAMIENTA INTEGRADORA?

SEGREGATION IN THE URBAN SPACE OF SOACHA

TRANSMILENIO AS AN INTEGRATING TOOL?

CARLos Augusto Moreno-Luna

\section{AROUITETURA E INDUSTRIALIZAÇÃO DAS CONSTRUÇÕES NA}

obra de JoÃo Filgueiras LIMA — LELÉ

ARCHITECTURE AND CONSTRUCTION'S INDUSTRIALIZATION IN THE WORK OF

JoĀo FilgueIrAs LIMA - LELÉ

Elza-Luli Miyasaka, Marieli Lukiantchuki, Michele C. B. Ferrari

CAIXETA, Marcio-Minto Fabricio

\section{EL DISEÑO DE LA VIVIENDA DE INTERÉS SOCIAL}

LA SATISFACCIÓN DE LAS NECESIDADES Y EXPECTATIVAS DEL USUARIO

THE DESIGN OF SOCIAL HOUSING

MEETING THE NEEDS AND USER EXPECTATIONS

Alex Leandro Pérez-PÉrez

EXPLORACIONES MORFOLÓGICAS EN TEXTURAS MODULARES

APROXIMACIONES DESDE EL OBJET TROUVÉ AL DISEÑO

نं PARAMÉTRICO

MORPHOLOGICAL EXPLORATIONS IN MODULAR TEXTURES

APPROXIMATIONS FROM OBJET TROUVÉ TO THE PARAMETRIC DESIGN

\section{CONSTRUCCIÓN EXPERIMENTAL DE UN SISTEMA}

